\title{
¿Cómo enseñar gramática a futuros publicistas? Apuntes sobre una experiencia de innovación docente en el grado de Publicidad
}

\section{How to teach grammar to future advertisers? Notes about a teaching innovation experience in the Advertising Degree}

ISAMARY ALDAMA PANDO

ORCID https://orcid.org/0000-0002-3324-7347

Universidad de Sevilla

Departamento de Lengua Española, Lingüistica y Teoría de la Literatura ialdama@us.es

DOI: http://dx.doi.org/10.12795/9788447231003.001

Pp.: 28-50 


\section{Introducción}

En este texto voy a describir la puesta en práctica de un Ciclo de Mejora en el Aula (CIMA) en la asignatura Lengua Española y Publicidad: saber idiomático y competencia comunicativa, impartida en el primer año del Grado en Publicidad y Relaciones Públicas. Es una asignatura troncal y tiene una carga docente de 6 créditos, con un total de 60 horas presenciales que, debido a las medidas aplicadas en el contexto de la crisis sanitaria de la COVID, se imparten desde el inicio del curso en la modalidad semipresencial, un tercio del grupo de manera presencial en el aula mientras la otra parte asiste por videoconferencia a través de la plataforma Blackboard Collaborate.

\section{Descripción del contexto y objetivos}

Según comentan los estudiantes que repiten la asignatura -toda la información de cursos anteriores se basa en las evaluaciones de los propios estudiantes, ya que antes de este cuatrimestre no había tenido experiencia docente en España-, esta se desarrollaba a partir del modelo didáctico tradicional o transmisivo (para una clasificación y caracterización de los modelos didácticos, véase García Pérez, 2000 y García Pérez y Porlán, 2017), con una metodología basada en una exposición ordenada en una clase magistral en la que el profesor dictaba su conferencia y los estudiantes escuchaban y tomaban notas en su papel de recipiente vacio que debe ser rellenado por el profesor (De Alba y Porlán, 2017: 38); luego tenían varias clases prácticas en las que llevaban al aula textos para analizarlos según los contenidos impartidos en clase -el modelo metodológico que De Alba y Porlán, 2017: 39-40 describen como basado en la teoría y su aplicación en la práctica-.

Habría que añadir también que la asignatura, en ese grupo y horario, generalmente ha sido compartida por dos, tres y hasta cuatro profesores. Esa situación dificulta

Ciclos de Mejora en el Aula (2020). Experiencias de Innovación Docente de la US Esta obra se distribuye con la licencia Creative Commons 
la enseñanza porque lo que debería verse como un bloque de contenidos relacionados entre sí termina siendo lo más parecido a varias asignaturas en una, con los criterios metodológicos de cada profesor y su modo particular de interpretar los contenidos impartidos.

Se han matriculado 72 estudiantes, de los cuales 11 son repetidores y no están obligados a asistir a clases, sin embargo, 5 de ellos participan regularmente en las sesiones. Por tanto, para describir una situación más cercana a la realidad del grupo, en lo relativo a estadísticas y evaluaciones, solo se contarán los 66 que sí están obligados a asistir a clase y lo hacen regularmente. Pese a que el horario no es favorable, el promedio de asistencia es de $83 \%$ y a medida que ha avanzado el curso ha ido en aumento, lo que demuestra que se sienten motivados con las clases.

El ciclo de mejora fue aplicado a finales de noviembre, en un período de restricciones de movilidad como medidas de contención al aumento de contagios por COVID, por lo que las clases se realizaron en la modalidad virtual.

\section{Diseño previo del CIMA}

El tema que correspondía al periodo de aplicación del CIMA era el 4, titulado Problemas de morfología nominal: el género y el número. Puesto que es un contenido sobre el que los estudiantes ya han trabajado en enseñanzas anteriores, el objetivo era que ellos fueran capaces de reconocer por sí mismos esas reglas que rigen la formación del género y el número y pudieran distinguir las situaciones problemáticas con respecto a la norma que se dan en algunos sustantivos. Por tanto, había que buscar un modo de hacer la clase atractiva, o al menos más dinámica. Y ahí es cuando entra en acción todo lo aprendido durante el Curso General de Docencia Universitaria. A continuación voy a explicar cómo diseñé las clases en función del ciclo de mejora.

Ciclos de Mejora en el Aula (2020). Experiencias de Innovación Docente de la US Esta obra se distribuye con la licencia Creative Commons 
El mapa de contenidos quedó estructurado a partir de una pregunta principal: ¿Cuáles son los problemas que nos encontramos al estudiar la morfología nominal? De la cual se derivaron varias preguntas clave según cada grupo de conceptos relacionados con la morfología nominal:

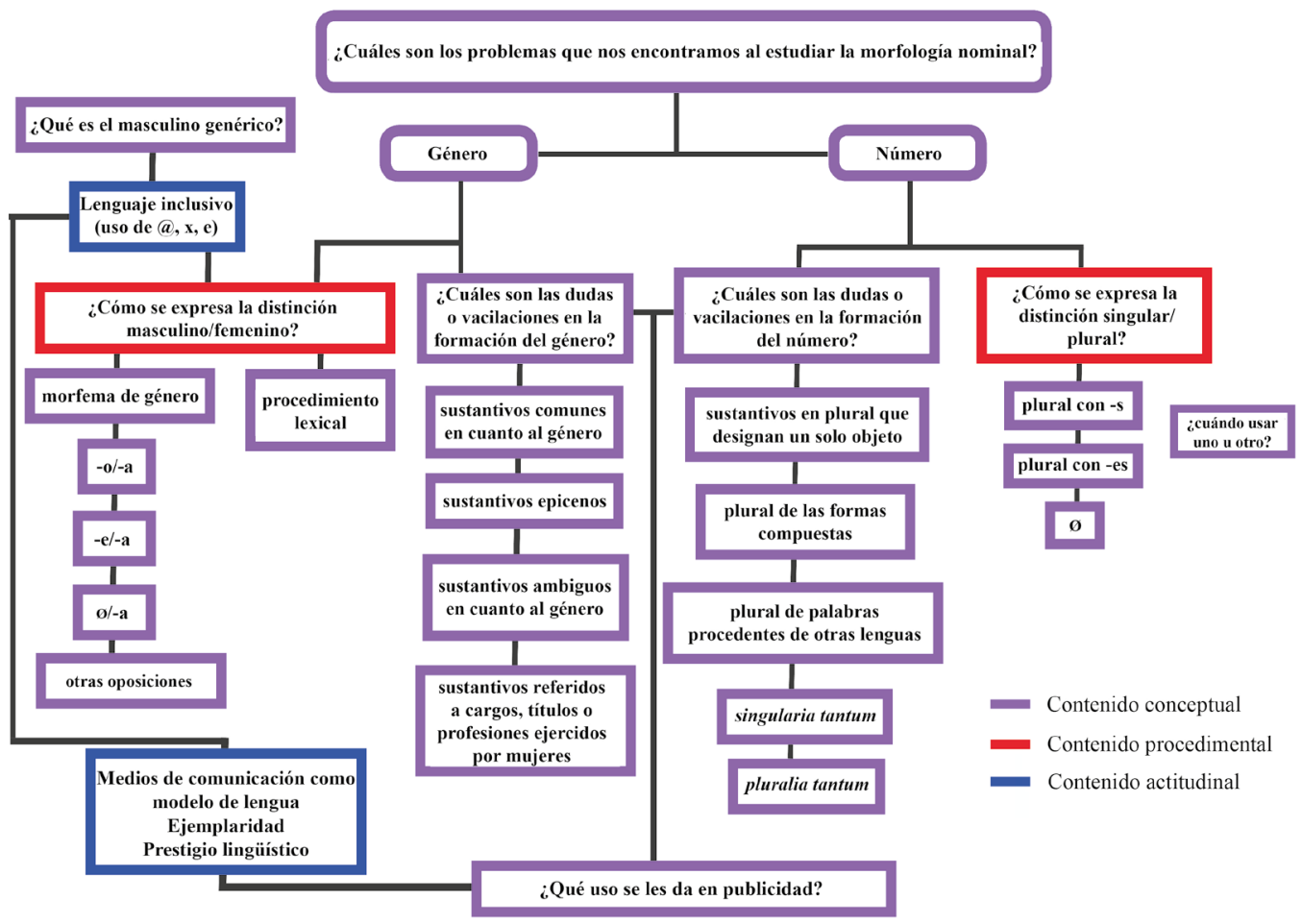

Figura 1. Mapa de contenidos y problemas.

Para dar respuesta a las problemáticas planteadas en el mapa de contenidos, programé una secuencia de actividades siguiendo un modelo metodológico posible en el que se daba especial importancia a las ideas de los estudiantes y al contraste de estas con lo planteado por especialistas. Este modelo metodológico podría resumirse en el siguiente esquema:

Ciclos de Mejora en el Aula (2020). Experiencias de Innovación Docente de la US Esta obra se distribuye con la licencia Creative Commons Reconocimiento-NoComercial-SinObraDerivada Internacional (CC BY-NC-ND 4.0.) 


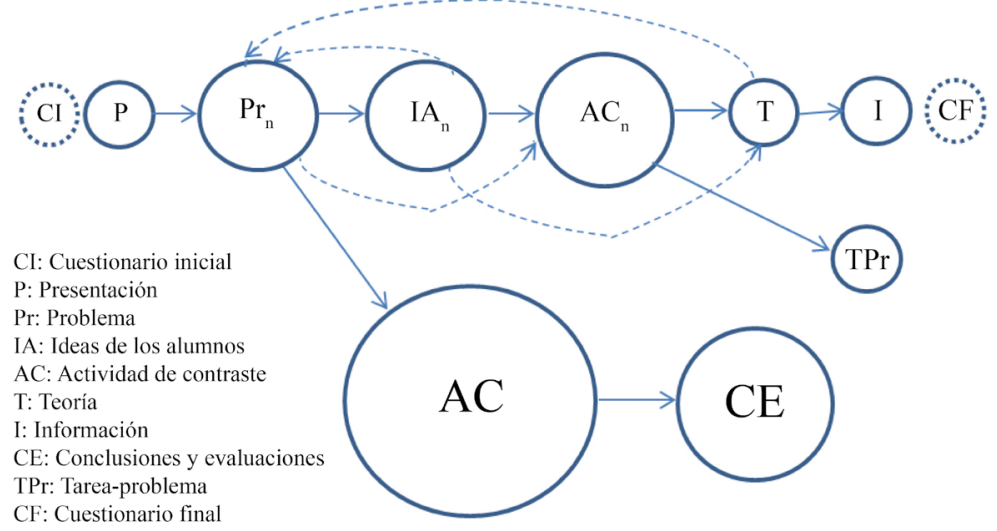

Figura 2. Modelo metodológico posible.

Como podemos ver, en el modelo se pone el énfasis en el trabajo con problemas a los que los propios estudiantes deben dar solución, también se destacan las ideas de los estudiantes y las actividades de contraste, demostrando así el interés en dar mayor participación al estudiante y en la reelaboración de sus ideas personales a partir de la interacción con los otros estudiantes o con la lectura de textos especializados. De estas actividades, la fundamental es la de contraste, de ahí que el círculo correspondiente sea el mayor de todos y solo esté acompañado por conclusiones y evaluaciones que realizan los estudiantes, sin intervención del profesor, excepto cuando sea necesario algún resumen teórico que no puedan hacer los propios estudiantes, o porque haya que dar alguna información sobre la estructura de las sesiones. Al mismo tiempo, las ideas de los estudiantes pueden dar paso al planteamiento de nuevos problemas o a cuestiones teóricas que pueden también generar nuevos problemas, interrelacionando así los pasos del modelo.

Antes de la aplicación del CIMA, envié a los estudiantes, a través de Google Drive, un cuestionario para evaluar los conocimientos de partida en relación con el tema -por

Ciclos de Mejora en el Aula (2020). Experiencias de Innovación Docente de la US Esta obra se distribuye con la licencia Creative Commons 
eso se representa en el modelo metodológico con líneas discontinuas, pues quedaba fuera de las 8 horas de aplicación del CIMA. Lo mismo sucede con el cuestionario final (la segunda aplicación de ese cuestionario inicial)-. Siguiendo las pautas dictadas por Rivero y Porlán (2017: 77-79), hice el envío con la justificación de que el cuestionario sería el punto de inicio para la organización de las clases de ese tema, por lo que requería total sinceridad y, para evitar que lo vieran como un examen en el que debían mostrar sus conocimientos teóricos, presenté las preguntas como si fuera una encuesta de la universidad. De hecho, les dije que yo no era la autora del cuestionario y que por tanto las respuestas no iban dirigidas a mí. Además les expliqué que debía mantenerse el anonimato y que, aun cuando la aplicación les pidiera una dirección de correo electrónico, debían escribir una dirección falsa, que debían recordar para una encuesta futura. Este es el cuestionario.

¡Hola!

Somos de la Unidad de Igualdad de la US. Estamos haciendo un sondeo entre los estudiantes para hacer algunas propuestas de modificación en el lenguaje empleado en la documentación de la US. Queremos que seas lo más sincero(a) posible y que respondas con naturalidad, sin usar términos técnicos. Solo nos interesa tu opinión como hablante.

1. ¿Qué opinas del uso de lax, la @ y la e en estas frases? Argumenta tu respuesta lo mejor posible.

"Amigues, sean todes bienvenides"

"Amig@s, sean tod@s bienvenid@s"

"Amigxs, sean todxs bienvenidxs"

2. ¿Qué modos conoces para marcar la diferencia hombre-mujer?

3. ¿Sabes qué es el "masculino genérico"? Explica este concepto con tus propias palabras.

4. Otro de los temas que nos preocupa es el uso de los plurales. ¿De qué modo puedes expresar la diferencia uno-muchos en los sustantivos?

Ciclos de Mejora en el Aula (2020). Experiencias de Innovación Docente de la US Esta obra se distribuye con la licencia Creative Commons 
5. ¿Cuál sería el plural de estos sustantivos o construcciones?

$\begin{array}{llll}\text { el lunes } & \text { palabraclave } & \text { la salud } & \text { el álbum } \\ \text { fecha limite } & \text { camión cisterna la sed } & \text { elsur }\end{array}$

Este cuestionario también fue usado para evaluar la evolución de los estudiantes y comprobar la efectividad del modelo propuesto, pues lo volví a enviar al finalizar la última sesión del CIMA. Más adelante se analizarán los resultados obtenidos.

Asimismo, las respuestas de los estudiantes fueron el punto de partida para diseñar las actividades con las que cumpliría los objetivos planteados a partir de las preguntas clave del mapa de contenidos, así como para identificar dónde estaban los problemas que debía resolver en clase. Además, sirvieron de base a los alumnos para debatir en cada sesión sobre sus propias ideas.

A continuación presento el diseño de las actividades con comentarios explicativos, para luego comparar con la realidad en la clase.

\section{Primera sesión (2 horas)}

Preguntas clave: ¿Cuáles son los problemas que nos encontramos al estudiar la morfología nominal? (Esta pregunta es la que estructura el tema, pero se responde al final del mismo). ¿Qué es el lenguaje inclusivo? ¿Cuál es la opinión de los estudiantes sobre el uso de “@”, “x”, "e”? ¿Qué es el masculino genérico?

Ciclos de Mejora en el Aula (2020). Experiencias de Innovación Docente de la US Esta obra se distribuye con la licencia Creative Commons 
Tabla 1. Secuencia de actividades de la primera sesión

\begin{tabular}{|c|c|c|}
\hline No. & Nombre & Descripción \\
\hline 1 & $\begin{array}{l}\text { (P) Presentación de la } \\
\text { clase }\end{array}$ & Duración: 10 min \\
\hline 2 & $\begin{array}{l}\text { (Pr) Planteamiento de } \\
\text { un problema }\end{array}$ & $\begin{array}{l}\text { Haciendo referencia explícita al cuestionario } \\
\text { que se ha realizado antes de la clase, se } \\
\text { plantean las dos primeras preguntas de este } \\
\text { (véase cuestionario). Duración: } 15 \mathrm{~min}\end{array}$ \\
\hline 3 & $\begin{array}{l}\text { (IA) Respuestas } \\
\text { individuales y debate }\end{array}$ & $\begin{array}{l}\text { Los alumnos irán anotando sus respuestas } \\
\text { y las compartirán con la clase. Se les pedirá } \\
\text { que tengan en cuenta las respuestas dadas } \\
\text { en el cuestionario inicial. Se irán anotando } \\
\text { en un documento que quedará a la vista } \\
\text { de todos en la pantalla compartida, para } \\
\text { contrastar las respuestas con lo que se verá } \\
\text { en la siguiente actividad. Duración: } 25 \text { min }\end{array}$ \\
\hline 4 & $\begin{array}{l}\text { (AC) Contraste } \\
\text { con opiniones de } \\
\text { especialistas y otros } \\
\text { hablantes }\end{array}$ & $\begin{array}{l}\text { Se proyectarán fragmentos de video } \\
\text { (entrevistas, conferencias, encuestas en la } \\
\text { calle) donde se reflejen las preocupaciones } \\
\text { actuales en lo que a representación de } \\
\text { género se refiere. Estos videos les servirán } \\
\text { a los alumnos como contraste de opiniones } \\
\text { con las respuestas dadas por ellos. Se } \\
\text { formarán grupos de trabajo para que cada } \\
\text { grupo analice las respuestas dadas en la } \\
\text { actividad anterior y las compare con lo dicho } \\
\text { por sus compañeros y por las personas que } \\
\text { hablan en los videos. Deberán responder } \\
\text { a la siguiente pregunta: Luego de ver las } \\
\text { opiniones analizadas, ¿sigues pensando } \\
\text { igual con respecto al uso de "@", "x" y “e"? } \\
\text { Si hubo algún cambio, argumenta por qué. } \\
\text { Duración: } 30 \text { min }\end{array}$ \\
\hline 5 & (T) Resumen teórico & $\begin{array}{l}\text { La profesora hará un resumen en el que } \\
\text { quede bien definido y explicado qué es el } \\
\text { masculino genérico y los dos conceptos } \\
\text { asociados a él (género gramatical y género } \\
\text { natural o sexo) que de algún modo, sin } \\
\text { mencionarlos, se han visto en la clase, a } \\
\text { partir de lo que se ve en los videos y que sin } \\
\text { darse cuenta los estudiantes mencionarán a } \\
\text { la hora de analizarlos. Duración: } 15 \text { min }\end{array}$ \\
\hline
\end{tabular}

Ciclos de Mejora en el Aula (2020). Experiencias de Innovación Docente de la US Esta obra se distribuye con la licencia Creative Commons 


\begin{tabular}{|l|l|l|}
\hline 6 & $\begin{array}{l}\text { (I) Informaciones } \\
\text { sobre próximas } \\
\text { sesiones }\end{array}$ & $\begin{array}{l}\text { Para motivar a los estudiantes en el estudio } \\
\text { del tema, los últimos } 25 \text { minutos de la clase } \\
\text { se tomarán para orientar la preparación } \\
\text { de un ejercicio de clase (en la tercera } \\
\text { sesión) que consiste en la simulación de un } \\
\text { problema profesional en el que tendrán que } \\
\text { poner en práctica lo visto en el tema, así } \\
\text { como buscar información para que formen } \\
\text { opiniones propias según el rol que deban } \\
\text { asumir en el ejercicio. Al terminar la clase } \\
\text { los estudiantes ya deben saber quién será } \\
\text { parte de su equipo de trabajo y qué papel } \\
\text { asumirá cada uno. }\end{array}$ \\
\hline
\end{tabular}

\section{Segunda sesión (2 horas)}

Preguntas clave: ¿Cómo se expresa la oposición masculino-femenino? ¿Cuáles son las dudas o vacilaciones en la formación del género?

Tabla 2. Secuencia de actividades de la segunda sesión

\begin{tabular}{|l|l|l|}
\hline No. & \multicolumn{1}{|c|}{ Nombre } & \multicolumn{1}{c|}{ Descripción } \\
\hline 1 & $\begin{array}{l}\text { (P) Presentación de } \\
\text { la clase }\end{array}$ & Duración: 10 min \\
\hline 2 & $\begin{array}{l}\text { (Pr) Planteamiento } \\
\text { de un problema }\end{array}$ & $\begin{array}{l}\text { Se pedirá a los alumnos que respondan a la } \\
\text { pregunta: ¿Qué modos o maneras conoces } \\
\text { para marcar la diferencia hombre-mujer? } \\
\text { Duración: 15 min }\end{array}$ \\
\hline 3 & $\begin{array}{l}\text { (IA) Respuestas } \\
\text { individuales y debate }\end{array}$ & $\begin{array}{l}\text { Las respuestas se anotarán en un documento } \\
\text { que quedará visible para todos en la pantalla } \\
\text { compartida. En otro documento se publicará } \\
\text { el resumen de las respuestas dadas en el } \\
\text { cuestionario. Duración: 15 min }\end{array}$ \\
\hline
\end{tabular}

Ciclos de Mejora en el Aula (2020). Experiencias de Innovación Docente de la US Esta obra se distribuye con la licencia Creative Commons 


\begin{tabular}{|c|c|c|}
\hline 4 & $\begin{array}{l}\text { (AC) Contraste con la } \\
\text { teoría }\end{array}$ & $\begin{array}{l}\text { Después de analizar y anotar las respuestas } \\
\text { se crearán grupos de trabajo y se pedirá } \\
\text { a cada grupo que compare las respuestas } \\
\text { dadas. Luego deberán leer un listado de } \\
\text { palabras y responder a las preguntas: A } \\
\text { partir de los métodos descritos antes, ¿cómo } \\
\text { sabemos que son masculinas o femeninas? } \\
\text { ¿Hay alguna otra manera de expresar la } \\
\text { diferencia hombre-mujer que no haya sido } \\
\text { mencionada? Identifícala y explica cuál sería } \\
\text { el procedimiento. Duración: } 12 \text { min }\end{array}$ \\
\hline 5 & ( $\mathrm{T}$ ) Resumen teórico & $\begin{array}{l}\text { Resumen y explicación de los diferentes } \\
\text { procedimientos identificados por los } \\
\text { estudiantes y alguno que no se haya } \\
\text { mencionado. Duración: } 12 \text { min }\end{array}$ \\
\hline 6 & $\begin{array}{l}\text { (Pr) Planteamiento } \\
\text { de un problema }\end{array}$ & $\begin{array}{l}\text { Se pedirá a los estudiantes que analicen } \\
\text { en grupo un conjunto de textos (imágenes } \\
\text { publicitarias, fragmentos de textos literarios, } \\
\text { transcripciones de diálogos) y determinen } \\
\text { cuáles serían las situaciones que generarian } \\
\text { dudas a la hora de identificar la oposición } \\
\text { masculino-femenino. Duración: } 15 \text { min }\end{array}$ \\
\hline 7 & $\begin{array}{l}\text { (IA) Respuestas del } \\
\text { análisis y puesta en } \\
\text { común }\end{array}$ & Duración: 20 min \\
\hline 8 & $\begin{array}{l}\text { (T) Exposición teórica } \\
\text { (resumen) }\end{array}$ & Duración: 12 min \\
\hline 9 & $\begin{array}{l}\text { (।) Exposición } \\
\text { informativa }\end{array}$ & $\begin{array}{l}\text { Para terminar la clase, se hará un } \\
\text { recordatorio de la actividad propuesta para } \\
\text { la tercera sesión. Duración: } 3 \text { min }\end{array}$ \\
\hline
\end{tabular}

\section{Tercera sesión (2 horas)}

Preguntas clave: ¿Cómo se expresa la oposición masculino-femenino? ¿Qué opinas del uso de “@”, “x”, "e”? ¿Qué uso se da en publicidad a las problemáticas de género? Pregunta secundaria: ¿Cuál es el papel de los medios de comunicación como modelo de lengua? 
Tabla 3. Secuencias de actividades de la tercera sesión

\begin{tabular}{|l|l|l|}
\hline No. & \multicolumn{1}{|c|}{ Nombre } & \multicolumn{1}{c|}{ Descripción } \\
\hline 1 & $\begin{array}{l}\text { (P) Presentación de } \\
\text { la clase }\end{array}$ & Duración: 8 min \\
\hline 2 & $\begin{array}{l}\text { (Pr) Presentación del } \\
\text { problema }\end{array}$ & $\begin{array}{l}\text { Explicación de la situación que se presentó } \\
\text { para dar pie al debate. Véase el Anexo I } \\
\text { con las instrucciones entregadas a los } \\
\text { estudiantes. Duración: 15 min }\end{array}$ \\
\hline 3 & $\begin{array}{l}\text { (AC) Realización del } \\
\text { debate }\end{array}$ & Duración: 1h 20 min \\
\hline 4 & $\begin{array}{l}\text { (CE) Conclusiones y } \\
\text { evaluación }\end{array}$ & $\begin{array}{l}\text { Los estudiantes que no exponen en el } \\
\text { debate tendrán la oportunidad de hacer } \\
\text { preguntas y funcionarán como jurado } \\
\text { para dar las conclusiones. Al final se hará } \\
\text { una votación para saber cuál ha sido } \\
\text { la propuesta mejor defendida, y se les } \\
\text { pedirá al azar que comenten sus opiniones } \\
\text { personales sobre el tema. Duración: 20 min }\end{array}$ \\
\hline
\end{tabular}

\section{Cuarta sesión (2 horas)}

Preguntas clave: ¿De qué maneras puedes expresar la diferencia uno-muchos en los sustantivos? ¿Cuáles son las dudas o vacilaciones en la formación del plural?

Tabla 4. Secuencia de actividades de la cuarta sesión

\begin{tabular}{|l|l|l|}
\hline No. & \multicolumn{1}{|c|}{ Nombre } & \multicolumn{1}{c|}{ Descripción } \\
\hline 1 & $\begin{array}{l}\text { (P) Presentación de la } \\
\text { clase }\end{array}$ & Duración: 10 min \\
\hline 2 & $\begin{array}{l}\text { (Pr) Presentación de } \\
\text { un problema }\end{array}$ & $\begin{array}{l}\text { Se pedirá a los alumnos que respondan a la } \\
\text { pregunta ¿De qué maneras puedes expresar } \\
\text { la diferencia uno-muchos en los sustantivos? } \\
\text { Podrán usar como base las respuestas dadas } \\
\text { en el cuestionario inicial. Duración: 15 min }\end{array}$ \\
\hline 3 & $\begin{array}{l}\text { (IA) Respuestas } \\
\text { individuales y debate }\end{array}$ & $\begin{array}{l}\text { Las respuestas se anotarán en un documento } \\
\text { que quedará a la vista de todos en la } \\
\text { pantalla compartida. Duración: 15 min }\end{array}$ \\
\hline
\end{tabular}

Ciclos de Mejora en el Aula (2020). Experiencias de Innovación Docente de la US Esta obra se distribuye con la licencia Creative Commons 


\begin{tabular}{|c|c|c|}
\hline 4 & $\begin{array}{l}\text { (Pr) Presentación de } \\
\text { un problema }\end{array}$ & $\begin{array}{l}\text { Se pedirá a los alumnos que lean un listado } \\
\text { de palabras y respondan a la pregunta: } \\
\text { ¿Cómo sabemos que están en singular o } \\
\text { plural? Duración: } 12 \text { min }\end{array}$ \\
\hline 5 & $\begin{array}{l}\text { (AC) Revisión del } \\
\text { ejercicio en grupos de } \\
\text { trabajo }\end{array}$ & $\begin{array}{l}\text { Revisión del ejercicio en grupos de trabajo, } \\
\text { donde cada estudiante dará su respuesta } \\
\text { y la explicará al resto. Se les pedirá que } \\
\text { consulten el Manual de la nueva gramática } \\
\text { de la lengua española en caso de dudas y } \\
\text { que comparen con lo anotado en la pantalla } \\
\text { según sus respuestas anteriores. Duración: } \\
20 \text { min }\end{array}$ \\
\hline 6 & (T) Exposición teórica & Duración: 12 min \\
\hline 7 & $\begin{array}{l}(\mathrm{Pr}) \text { Planteamiento de } \\
\text { un problema }\end{array}$ & $\begin{array}{l}\text { Los estudiantes deberán analizar un } \\
\text { conjunto de textos (imágenes publicitarias, } \\
\text { fragmentos de textos literarios, } \\
\text { transcripciones de diálogos) para determinar } \\
\text { de qué modo se escribiría el plural de } \\
\text { palabras o expresiones que causarían dudas } \\
\text { (entre ellos, los sustantivos y expresiones } \\
\text { que se usaron en el cuestionario inicial). } \\
\text { Duración: } 15 \text { min }\end{array}$ \\
\hline 8 & $\begin{array}{l}\text { (AC) Debate y } \\
\text { contraste }\end{array}$ & $\begin{array}{l}\text { Se crearán grupos para que los estudiantes } \\
\text { debatan las respuestas y lleguen a un } \\
\text { acuerdo para exponer una respuesta grupal. } \\
\text { Se les pedirá que consulten el Manual de } \\
\text { la nueva gramática de la lengua española. } \\
\text { Una vez elaborada la respuesta, cada grupo } \\
\text { debería ser capaz de identificar qué ocurre } \\
\text { en esos casos especiales. Duración: } 20 \text { min } \\
\text { Nota: La profesora solo intervendrá para } \\
\text { guiar la actividad o, en caso de que sea } \\
\text { necesario, para alguna aclaración teórica que } \\
\text { quede como resumen. }\end{array}$ \\
\hline
\end{tabular}

Ciclos de Mejora en el Aula (2020). Experiencias de Innovación Docente de la US Esta obra se distribuye con la licencia Creative Commons Reconocimiento-NoComercial-SinObraDerivada Internacional (CC BY-NC-ND 4.0.) 


\begin{tabular}{|l|l|l|}
\hline 9 & $\begin{array}{l}\text { (TPr) Tarea } \\
\text { (planteamiento de un } \\
\text { problema) }\end{array}$ & $\begin{array}{l}\text { Cada grupo de trabajo debe buscar ejemplos } \\
\text { reales de cómo se reflejan los contenidos } \\
\text { vistos en clase. El problema quedaría } \\
\text { enunciado del siguiente modo: En nuestra } \\
\text { vida cotidiana a veces tenemos vacilaciones } \\
\text { en el dominio de las reglas gramaticales, } \\
\text { relacionados fundamentales con la } \\
\text { morfología de los sustantivos. Busca tres } \\
\text { ejemplos reales donde se vean reflejados } \\
\text { los problemas que hemos visto en clase } \\
\text { relacionados con el género y el número de } \\
\text { los sustantivos. Muestra a tus compañeros } \\
\text { qué problema has identificado y explícalo. }\end{array}$ \\
\hline
\end{tabular}

\section{Aplicación del CIMA}

Tuve que hacer modificaciones sobre la marcha, pero eso no fue impedimento para el desarrollo del CIMA; al contrario, enriqueció la experiencia y al final las clases superaron las expectativas. A continuación haré un relato resumido de cada sesión, basada en las notas que tomé en un diario, según las recomendaciones expuestas en Rivero y Porlán (2017: 86-88). Debo decir que fue una herramienta muy útil porque me obligó a estar pendiente de cada detalle de la clase para poder realizar una evaluación más completa de todo lo que sucedió en las sesiones y comparar lo planificado con lo que realmente ocurrió.

En la primera sesión, durante los primeros treinta minutos, la clase se desarrolló tal como estaba diseñada. Una vez que los alumnos tuvieron la oportunidad de compartir sus respuestas individuales, todo fue completamente diferente. No solo con respecto al primer momento de la sesión, sino en relación con lo ocurrido anteriormente en el curso. En clases anteriores casi tenía que obligarlos a hablar o a veces solo hablaban los mismos. En esta oportunidad, prácticamente todos dieron su opinión, ya fuera en el chat o hablando por el micrófono. Viendo lo motivados que estaban, no puse límites en el tiempo y lo que estaba

Ciclos de Mejora en el Aula (2020). Experiencias de Innovación Docente de la US Esta obra se distribuye con la licencia Creative Commons 
planificado para que durara 25 minutos terminó ocupando unos 40.

En la siguiente actividad también hubo un debate que no esperaba. Se sintieron tan seguros y motivados que hasta criticaron a los académicos y sus argumentos con respecto al uso de los recursos analizados. Una vez más, la actividad ocupó más tiempo del planificado, pero me sentí muy contenta al ver cómo interactuaban en el grupo y analizaban con detenimiento lo dicho por los otros. Confieso que llegó un momento en el que no sabía cómo parar el debate porque todos se involucraron en la discusión. Al punto de que no pude realizar el resumen que tenía planificado para que les quedaran bien claros los conceptos relacionados con lo debatido. Pero no hizo falta, pues a medida que surgían preguntas en el debate se iban aclarando esos conceptos.

Al final solo me quedaron 15 minutos de clase para explicarles cómo se desarrollaría el ejercicio que tendría lugar en la tercera sesión. Cuando les dije que haríamos un debate a partir de una situación de la vida real y que la participación era voluntaria, tuvieron dudas. Pero cuando les envié el texto con las instrucciones de desarrollo, hubo más interés, que se completó con el incentivo de que les otorgaría un punto extra para la calificación final.

En la segunda sesión hubo problemas con el acceso a la red de la US, por lo que la clase empezó más tarde, a la espera de que la mayor cantidad de estudiantes pudiera conectarse. Los problemas con el acceso también provocaron dificultades para la entrega del ejercicio que les había orientado en sesiones anteriores, cuya fecha límite era ese día. Además, la mayoría no sabía cómo trabajar en la plataforma para entregar la tarea o consultar los materiales de estudio que les había estado compartiendo en sesiones anteriores. Entonces, tuve que dedicar parte de la clase a explicarles dónde encontrar la información y cómo responder la tarea. Eso tomó media hora, por lo que tuve que adaptar las actividades que tenía planificadas: se

Ciclos de Mejora en el Aula (2020). Experiencias de Innovación Docente de la US Esta obra se distribuye con la licencia Creative Commons 
eliminó el resumen de la clase anterior y se pasó directamente a la pregunta: ¿Qué modos conoces para marcar la diferencia hombre-mujer? Aquí pude recuperar parte del tiempo, pues solo mencionaron la oposición morfológica con los morfemas -o/-a. Sin embargo, con el ejercicio siguiente, sí identificaron otros problemas relativos a la expresión del género. Sobre todo porque cambié el modo de preguntar y el ejercicio, ya que vi que no les quedaba muy claro qué buscaba con la pregunta. Utilicé un cuestionario de Wooclap que tenía preparado para otra clase; en él debían decir cuál era el femenino de un grupo de palabras, para que a partir de la comparación entre el masculino y el femenino extrajeran las conclusiones teóricas.

Creo que fue la mejor decisión, pues se mostraron bastante motivados con el ejercicio y la competencia que se generó al ver proyectada en la pantalla la evolución de las respuestas. Sirvió también para hacer aclaraciones ortográficas, como en el caso de barón, que muchos confundieron con varón (sexo) y escribieron hembra. Asimismo, el ejercicio permitió que los estudiantes elaboraran la teoría desde el ejercicio y yo solo intervine para hacer algunas aclaraciones.

Con la realización de la actividad 6 demostraron que habían captado las diferencias, pues lograron identificar los problemas relacionados con el tema de la clase y los explicaron muy bien, empleando nombres técnicos que no se habían mencionado, pero que ellos conocían de estudios anteriores. Por tanto, la exposición teórica que tenía planificada no fue necesaria. Además de que no me iba a alcanzar el tiempo. Por tanto, les di la posibilidad de que se estudiaran en la casa el resumen que les había preparado en una presentación de Power Point y que completaran la información con el Manual de gramática de la RAE que les había facilitado como parte de la bibliografía.

Los últimos 15 minutos los empleé para aclarar las dudas sobre el debate que se realizaría en la siguiente sesión

Ciclos de Mejora en el Aula (2020). Experiencias de Innovación Docente de la US Esta obra se distribuye con la licencia Creative Commons 
y orientarlos en la búsqueda de información para preparar las posiciones que debían defender.

En cuanto a la tercera sesión, debo decir que los resultados fueron impresionantes. Se notó la preparación de los estudiantes, pues buscaron datos de investigaciones científicas, llevaron presentaciones y videos para apoyar sus opiniones, y usaron imágenes publicitarias reales para demostrar sus puntos. Yo solo intervine para organizar la actividad y hacerles un par de preguntas para buscar alguna reflexión. La sesión fue tan productiva que por primera vez terminé la clase después del tiempo reglamentario.

En la cuarta sesión se trataron los contenidos relacionados con el número y la oposición-singular/plural. Aunque les costó identificar las reglas para la formación del plural, en sentido general la sesión trascurrió sin cambios significados. Salvo que el resumen teórico se extendió más de lo planificado, a petición de los estudiantes.

Quedaron muy motivados con la tarea de buscar ellos ejemplos de la vida real en los que se reflejen las problemáticas vistas en clase. En general, en ese tipo de actividad se muestran más participativos, por eso siempre que tengo la oportunidad les llevo a la clase imágenes para que las analicen en relación con lo aprendido o les oriento que ellos las busquen para presentarlas en clase.

\section{Evaluación del aprendizaje}

Como adelantaba cuando presenté el cuestionario, una vez terminada la aplicación del CIMA volví a enviarlo con la intención de comprobar cuánto habían avanzado los estudiantes con respecto a sus ideas iniciales. De los 66 estudiantes, solo 30 completaron el primer cuestionario, y por eso pedí que esos 30 completaran el segundo. Sin embargo, solo 20 lo hicieron en el tiempo solicitado y por eso solo pude evaluar el aprendizaje de esos 20, pero considero que es un buen número para tener una medida de cómo están los estudiantes. 
De manera general, se puede decir que hubo una evolución con respecto al cuestionario inicial. El método tuvo resultados favorables, ya que entre una aplicación y otra se nota que los estudiantes superaron los obstáculos iniciales en cuanto al análisis de cuestiones que requerían conocimientos o habilidades de abstracción, como en la pregunta 1, donde debían dar su opinión sobre el uso de "@”, " $x$ " y "e" como recurso de lenguaje inclusivo. En la primera aplicación del cuestionario, 45\% de los que respondió se quedó en los niveles más bajos de respuesta, pues: 1) solo respondieron con un "sí", "de acuerdo" o "bien" $(25 \%), 2)$ respondieron destacando el contexto en el que se consideran (in)correctos o 3) respondieron mencionando la finalidad del uso (para ser inclusivo, por moda), por lo tanto no cumplían el objetivo del ejercicio y por eso, a pesar de estar representados en tres escalones diferentes, están prácticamente a la misma altura. En los otros niveles, las respuestas son más elaboradas y dan más elementos explicativos a medida que suben los escalones, pero la mayor parte de los estudiantes se queda en los niveles intermedios.

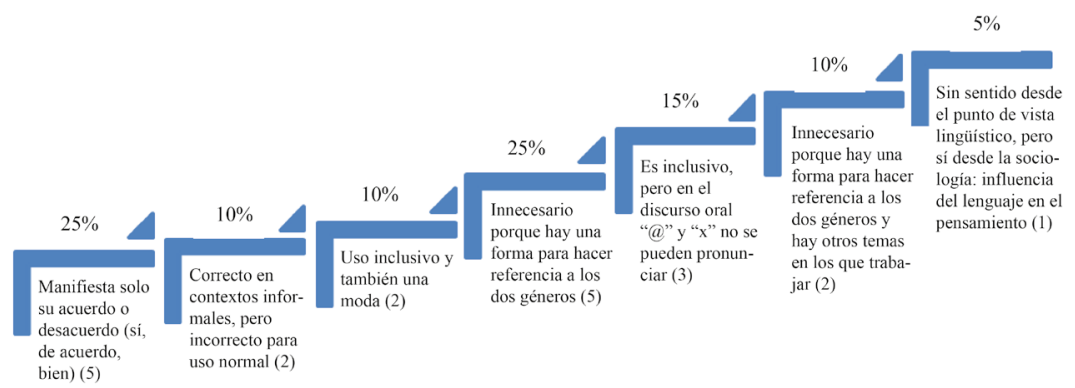

Figura 3. Escalera inicial de la pregunta 1 del cuestionario

Mientras que en la segunda aplicación la mayor parte de los estudiantes está en los niveles superiores, dando argumentos más cercanos a lo esperado para explicar la respuesta, aunque aún quedan algunos en cuyas 
respuestas se tienen más en cuenta cuestiones prácticas en cuanto al uso del recurso analizado en vez de hacer las conceptualizaciones abstractas que requiere el ejercicio para explicar y valorar lo analizado.

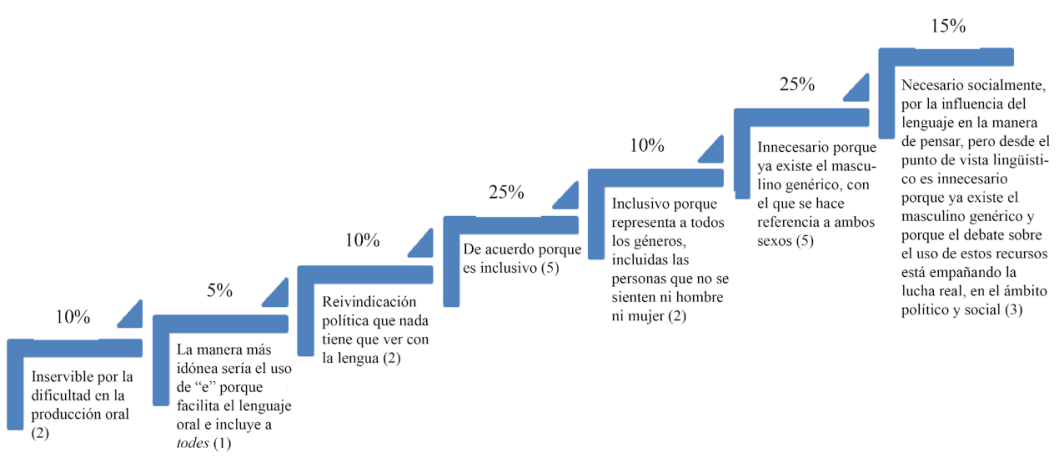

Figura 4. Escalera final de la pregunta 1 del cuestionario

Por limitaciones de espacio, solo se puede hacer referencia a la escalera de aprendizaje de una pregunta a modo de ejemplo de la evaluación realizada, pero habría que destacar también que la pregunta que tuvo cambios más evidentes en sus respuestas fue la 5, ya que entre una y otra aplicación un mayor número de estudiantes comprendió las reglas de formación del plural y, por tanto, sus respuestas mejoraron, como demuestran los siguientes gráficos, en los que podemos notar que en la segunda parte hay menos estudiantes en la columna de "No reconoce la regla".

Ciclos de Mejora en el Aula (2020). Experiencias de Innovación Docente de la US Esta obra se distribuye con la licencia Creative Commons 

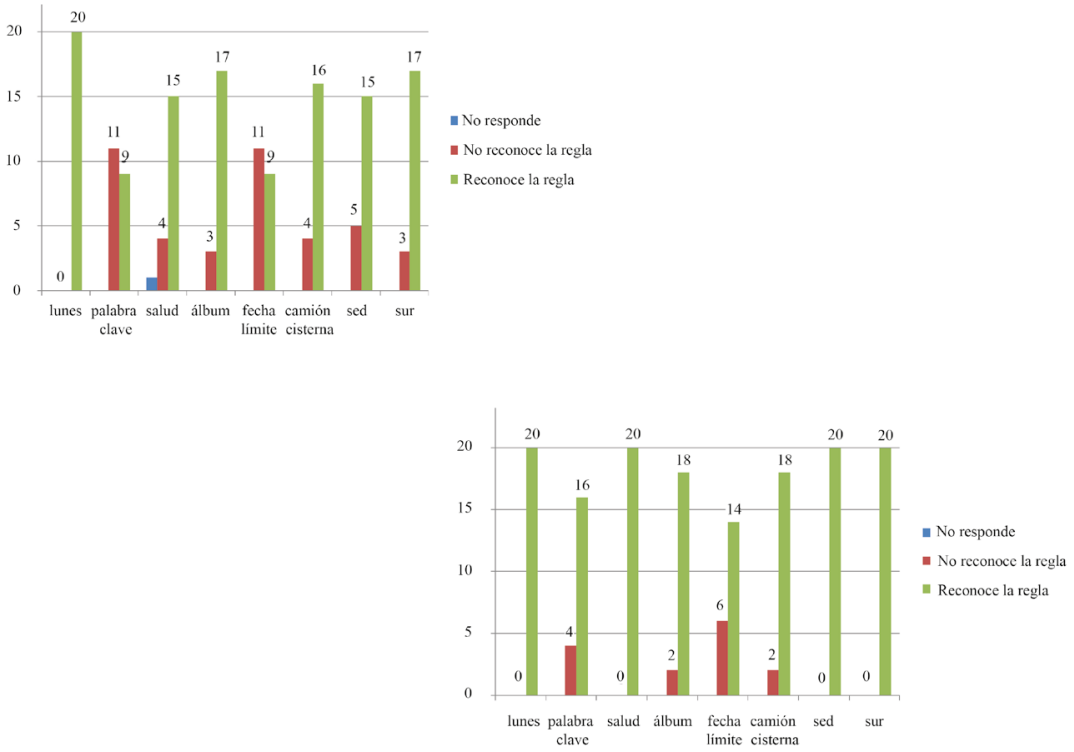

Figuras 5 y 6 . Gráficos de las respuestas a la pregunta 5 de los cuestionarios inicial y final

\section{Evaluación del CIMA}

En mi modelo didáctico siempre he estado cercana al enfoque constructivista y he incorporado en la metodología una parte importante de actividades de contraste y otras basadas en la solución de problemas. Además de que siempre he buscado una mayor participación del estudiante con preguntas de clase para ver cómo evoluciona el proceso de aprendizaje y para que a través de las respuestas y sus conclusiones personales se produzca de manera colectiva el desarrollo teórico de los contenidos. Gracias a la realización de este ciclo de mejora, he comprobado una vez más que la participación de los estudiantes en la clase, dejarlos extraer conclusiones por si solos a través del análisis en la práctica, es muy bueno. Sobre todo en esta asignatura en la que se trabajan contenidos que ya ellos conocen (o al menos deben conocer) y lo que se hace es ponerles en situación real para que puedan poner en práctica esos conocimientos.

Ciclos de Mejora en el Aula (2020). Experiencias de Innovación Docente de la US Esta obra se distribuye con la licencia Creative Commons 
Mi intención como profesora no es tanto que los alumnos sean capaces de memorizar el contenido teórico y las reglas gramaticales u ortográficas dictadas en clase, sino que pongan en práctica, en el análisis y la producción de contenidos, lo visto en la asignatura, y que ellos por sí solos sean capaces de llegar a conclusiones a partir de los ejercicios realizados en clase -el aprendizaje mediante el descubrimiento personal al que hacía referencia Piaget (1999) - y el contraste con otras opiniones, en fin, aplicar una metodología que permita el aprendizaje por medio de la interacción y el debate de las ideas de los estudiantes en contraste con otras.

Por esta razón, para futuros CIMA, seguiré aplicando el método de presentarles problemas para que ellos, por medio del debate en grupo y la puesta en contraste de sus ideas con el análisis de teoría u opiniones de otros, puedan hacer sus propios análisis. Asimismo, seguiré organizando actividades de debate en los temas que serán problemáticos para ellos en el futuro y en los que deben aplicar los conocimientos aprendidos en clase, además de demostrar sus capacidades en la toma de decisiones basados en aprendizaje adquirido y la lectura crítica de bibliografía, y sus habilidades para argumentar y defender sus opiniones.

Ciclos de Mejora en el Aula (2020). Experiencias de Innovación Docente de la US Esta obra se distribuye con la licencia Creative Commons 
Palabras clave: Lengua Española, Publicidad, Docencia Universitaria, Experimentación Docente Universitaria

Keywords: Spanish Language, Advertising, University Teaching, University Teaching Experimentation

\section{Referencias bibliográficas}

Aravena C.F. (2013). Desarrollando el modelo colaborativo en la formación docente inicial: la autopercepción del desempeño profesional del practicante en acción. Estudios Pedagógicos, XXXIX (1), 27-44.

Bain, K. (2007). Lo que hacen los mejores profesores universitarios. Valencia: Publicaciones de la Universidad de Valencia.

De Alba, N. y Porlán, R. (2007). La metodología de la enseñanza. En R. Porlán (coord.), Enseñanza universitaria. Cómo mejorarla (pp. 37-53). Madrid: Ediciones Morata.

Finkel, D. (2008). Dar clases con la boca cerrada. Valencia: Servicio de Publicaciones de la Universidad de Valencia. García Pérez, F. (2000). Los modelos didácticos como instrumento de análisis y de intervención en la realidad educativa. Biblio 3W. Revista Bibliográfica de Geografía y Ciencias Sociales, 207, 1-12.

García Pérez, F. y Porlán, R. (2017). Los principios didácticos y el modelo didáctico personal. En R. Porlán (coord.), Enseñanza universitaria. Cómo mejorarla (pp. 93-104). Madrid: Ediciones Morata.

Piaget, J. (1999). La psicología de la inteligencia. Barcelona: Crítica.

Rivero, A. y Porlán, R. (2017). La evaluación en la enseñanza universitaria. En R. Porlán (coord.), Enseñanza universitaria. Cómo mejorarla (pp. 73-91). Madrid: Ediciones Morata.

Ciclos de Mejora en el Aula (2020). Experiencias de Innovación Docente de la US Esta obra se distribuye con la licencia Creative Commons 


\section{Anexo I}

Instrucciones para la actividad de debate (sesión 3).

Se van a crear cuatro grupos de trabajo con las siguientes características:

Grupo I: Son una prestigiosa compañía de publicidad que ha sido contratada por una organización feminista que trabaja por que la lucha por la igualdad de género sea tenida en cuenta en las políticas públicas. Para ello, la organización les pide que deben usar los siguientes recursos defendidos por el lenguaje inclusivo: “x”, "-e”, “@” para marcar la inclusión de todas las opciones o preferencias de género. Los miembros de la compañía se muestran reticentes frente a la propuesta y deciden acudir a diferentes instancias para documentarse. Luego de escuchar a todas las partes, deben tomar una decisión basados en la respuesta que más los convenció.

Una sugerencia: para apoyar la exposición de la decisión que tomarán, podrían crear una imagen de cartel (no tiene que ser nada profesional) en la que se usen los recursos solicitados por la organización feminista y otro en el que no se empleen. Y así, explicando lo positivo de una posición frente a la otra, pueden hablar todos, o la gran mayoría.

Grupo II: Son una organización feminista que trabaja por que la lucha por la igualdad de género sea tenida en cuenta en las políticas públicas. Contratan a una compañía de publicidad para que les haga una campaña que contribuya a visibilizar su trabajo. Para ello, piden a la organización que tenga en cuenta en el trabajo el uso de los siguientes recursos defendidos por el lenguaje inclusivo: "x", “-e", “@” para marcar la inclusión de todas las opciones o preferencias de género. Ante la reticencia de la compañía, deben defender su posición y demostrar por qué es necesario el uso de esos recursos.

Grupo III: Representan a la RAE como institución normativizadora. Deben mostrar la posición de la Academia Ciclos de Mejora en el Aula (2020). Experiencias de Innovación Docente de la US
Esta obra se distribuye con la licencia Creative Commons 
con respecto al uso de los recursos sujetos a análisis y explicar por qué no deben usarse.

Grupo IV: Representan el papel del Ministerio de Igualdad, y como tal tienen la obligación de defender la igualdad de género. Deberán investigar para saber cuál es la posición real del ministerio y como tal defender esa opinión.

Cada grupo debe estar integrado por 5 estudiantes. Cada exposición debe tener una duración de 20 minutos. Pueden usar fotos, videos, presentaciones de Power Point y todo lo que necesiten para realizar la exposición. El resto de la clase deberá estar atento a lo que suceda en el debate, porque después tendrán la oportunidad de hacer preguntas y funcionarán como jurado. Al final se hará una votación para saber cuál ha sido la propuesta mejor defendida, y se les pedirá al azar que comenten sus opiniones personales sobre el tema. Al tiempo que valoren lo dicho por sus compañeros a partir de los conceptos de ejemplaridad y prestigio lingüístico (vistos en temas anteriores), relacionados también con el papel de los medios de comunicación como modelo de lengua.

Ciclos de Mejora en el Aula (2020). Experiencias de Innovación Docente de la US Esta obra se distribuye con la licencia Creative Commons 